\title{
Successful Induction of Lactation in a Barren Thoroughbred Mare: Growth of a Foal Raised on Induced Lactation and the Corresponding Maternal Hormone Profiles
}

\author{
Kenji KOROSUE ${ }^{1) *}$, Harutaka MURASE $^{1)}$, Fumio SATO ${ }^{1)}$, Mutsuki ISHIMARU ${ }^{1)}$, Takehiro HARADA ${ }^{2}$, \\ Gen WATANABE ${ }^{2)}$, Kazuyoshi TAYA ${ }^{2)}$ and Yasuo NAMBO ${ }^{1)}$ \\ 1) Hidaka Training and Research Center, Japan Racing Association, 535-13 Aza-Nishicha, Urakawa-cho, Urakawa-gun, Hokkaido \\ 057-0171, Japan \\ ${ }^{2)}$ Laboratory of Veterinary Physiology, Department of Veterinary Medicine, Faculty of Agriculture, Tokyo University of Agriculture and \\ Technology, 3-5-8 Saiwai-cho, Fuchu, Tokyo 183-8509, Japan
}

(Received 28 January 2012/Accepted 19 March 2012/Published online in J-STAGE 2 April 2012)

\begin{abstract}
The purpose of this study was to demonstrate that a barren parous Thoroughbred mare with lactation induced by hormonal treatment can be introduced to an orphan foal at the same farm and that the mare can become pregnant after the end of the hormonal treatment. An additional purpose was to investigate the changes in the plasma concentrations of prolactin, estradiol-17 $\beta$, progesterone, folliclestimulating hormone, and luteinizing hormone before, during, and after hormonal treatment. The difference in body weight between the adopted foal and the control foals, which were at the same farm and raised by their natural mothers, was $17 \mathrm{~kg}$ at 24 weeks old, when the foals were weaned. However, the adopted foal and the control foals had almost the same weight at 35 weeks old and later. The first ovulation after hormonal treatment was confirmed 10 days after the end of hormonal treatment and then the normal estrous cycle resumed. Furthermore, the changes in plasma progesterone, estradiol-17 $\beta$, follicle-stimulating hormone, and luteinizing hormone showed regular patterns after the first ovulation. Conception was confirmed in the fifth ovulation. Meanwhile, another study demonstrated that conception was confirmed in the first ovulation after hormonal treatment. The present study is the first to demonstrate the hormonal profiles during and after induction of lactation in a Thoroughbred mare. This approach is useful for solving the economic and epidemic problems of introducing a nurse mare to an orphan foal.

KEY WORDS: hormonal treatment, horse, induction of lactation.
\end{abstract}

doi: 10.1292/jvms.12-0035; J. Vet. Med. Sci. 74(8): 995-1002, 2012

Foaling sometimes results in an orphan foal due to the death of a mare from causes such as colic or uterine hemorrhage, or the mare's rejection of her foal. To raise an orphan foal, it is necessary to find an alternative milk source for the foal, such as bottle-feeding or acquiring a nurse mare. Although many orphan foals have been successfully fed from a bottle [21], hand-rearing from a bottle is a formidable task, because foals must typically be fed every $2 \mathrm{hr}$ during the first week of life. Furthermore, hand-raised foals often become difficult to manage and break because they are not respectful of humans. For these reasons, it is recommended that a nurse mare should be introduced to an orphan foal. However, when a nurse mare is introduced to an orphan foal, there are some concerns regarding the mare's health, including the history of vaccination and deworming, and test results for equine infectious anemia [23].

In recent years, some reports have demonstrated that lactation without a preceding pregnancy has been induced using a treatment that includes estrogen, progesterone, and

*Correspondence to: Korosue, K., Hidaka Training and Research Center, Japan Racing Association, 535-13 Aza-Nishicha, Urakawa-cho, Urakawa-gun, Hokkaido 057-0171, Japan.

e-mail: Kenji_Korosue@jra.go.jp

C2012 The Japanese Society of Veterinary Science a dopamine D2 antagonist aimed at increasing prolactin (PRL) secretion in mares [2, 6, 31]; this has similarly been shown in cows $[1,3,30]$. Furthermore, another study has shown that there is no significant difference in body weight between the foals adopted by mares with induced lactation and the control foals that remained with their natural mothers at the age of weaning [4]. Studies using these treatment protocols have indicated that approximately $80 \%$ of treated non-pregnant mares lactated sufficiently to raise an orphan foal [31].

It is recommended that mild-mannered mares, such as Paints, Appaloosas, and Quarter Horses, be chosen to undergo induced lactation, because it is important that a nurse mare is gentle, has strong maternal instincts, provides a moderate amount of milk, and rarely rejects a foal, and these breeds are easier to use than a Thoroughbred [22]. Therefore, there is no report to demonstrate that a Thoroughbred mare with induced lactation can raise an orphan foal until weaning age. If a barren parous Thoroughbred mare is induced to lactate using a hormonal treatment and then used as a nurse mare to raise an orphan foal on the same Thoroughbred farm, it is possible to solve the high cost of leasing a nurse mare and the prevention of epidemics in introducing a nurse mare to an orphan foal. Furthermore, if the barren parous mare with induced lactation can become 
pregnant after the end of hormonal treatment so that she can give a birth in the next season, this becomes a considerable economic advantage for the owner of a Thoroughbred farm. However, there is no report to indicate whether the hormonal treatment to induce lactation as a nurse mare affects the mare's subsequent pregnancy.

The purpose of this study is to demonstrate that a barren parous Thoroughbred mare with lactation induced by hormonal treatment can be introduced as a nurse mare to a Thoroughbred orphan foal kept on the same farm and will raise the orphan foal until weaning age and that the mare with induced lactation can become pregnant after the end of hormonal treatment. Additionally, we also investigated the changes in the plasma concentrations of PRL, estradiol$17 \beta$, progesterone, follicle-stimulating hormone ( $\mathrm{FSH})$, and luteinizing hormone ( $\mathrm{LH}$ ) before, during, and after hormonal treatment.

\section{MATERIALS AND METHODS}

The study was carried out as two experiments. In the first experiment (Experiment 1), a Thoroughbred mare with lactation induced by a hormonal treatment was introduced to a Thoroughbred orphan foal. In the second experiment (Experiment 2), the possibility of that mare becoming pregnant after the end of the hormonal treatment was studied. These experiments were approved by the Animal Care and Use Committee at Hidaka Training and Research Center.

Experiment 1: Case Report on the Induction of Lactation and Introduction of that Mare to an Orphan Foal

Animals: In one Thoroughbred mare that was 20 years old, $623 \mathrm{~kg}$ body weight, non-pregnant, non-parturient, and had previously delivered and nursed 12 foals, lactation was induced by hormonal treatment. The mare was housed at night, grazed every day, and was fed three times a day based on the calculated requirements (approximately $31 \mathrm{Mcal}$ ) for natural nursing mares from the first day of hormonal treatment. The mare was kept under an artificial photoperiod (14.5 hr light: $9.5 \mathrm{hr}$ darkness; light intensity: 100 lux) for about 8 weeks before the beginning of hormonal treatment, with January 7 th as the start date. Furthermore, this artificial photoperiod treatment was maintained until the second ovulation after the end of all treatments to advance estrus cyclicity and to improve the PRL secretion in response to sulpiride treatment.

A Thoroughbred orphan foal that was rejected by his own dam due to agalactia from 4 days old was adopted by the mare with induced lactation at 23 days old. The foal was fed 5 to $12 l$ of artificial milk (10-12 times per $0.4-1 l$ per feeding for 10-12 feedings) using a medication syringe from 4 days old until adoption at 23 days old, because his body weight was lower than that at birth.

The natural dam did not always show aggressiveness, such as kicking and biting toward the foal, but kicked, bit, and refused suckling when the foal tried to suckle. On the other hand, the natural dam allowed him to suckle only when she was restrained by an attendant. Therefore, while the natural dam was restrained by an attendant, the foal was given artificial milk using a medication syringe from the opposite side from where the foal tried to suckle, so that he would not to forget how to suckle before the time of adoption. Furthermore, the foal was supplemented with approximately $5 l$ of artificial milk per day ( $1 l$ per feeding and 5 feedings per day) for 3 weeks after adoption in the same way as above using a medication syringe, because milk production was considered to be low after the induction of lactation compared to normal lactation.

Hormonal treatment: Hormonal treatment in this study was modified from the protocol used in a previous study [6]. The protocol for inducing lactation by hormonal treatment in this study is presented in Table 1. Altrenogest (72 mg/ day per os; Regu-mate, Intervet, Millsboro, DE, U.S.A.) and estradiol-benzoate $(7.1 \mathrm{mg} /$ day i.m.; Estradiol Injection KS, Kyoritsu Seiyaku Corporation, Tokyo, Japan) were administered on Days 1 to 14. Estradiol-benzoate (50 mg i.m.; Estradiol Injection KS, Kyoritsu Seiyaku Corporation) and prostaglandin (5 mg i.m.; Planate, Intervet, Osaka, Japan) were administered on Day 8 and sulpiride $(1 \mathrm{mg} / \mathrm{kg}, \mathrm{i} . \mathrm{m}$.; Pyrikappl IM Inj. 50 mg, Isei Co., Inc., Yamagata, Japan) was administered twice daily on Days 8 to 22. Milking was started on Day 11 and performed 5-7 times per day between 0600 and 2200 by hand. Oxytocin (5 IU, i.m., Oxytocin Injection, Nagase Medicals Co., Ltd., Hyogo, Japan) was administered approximately $2 \mathrm{~min}$ before milking. The quantity of milk production was measured each time. The mare with induced lactation was introduced to the orphan foal on Day 14 (after 4 days of milking), because production reached $800 \mathrm{~m} l$ per milking.

Artificial insemination after hormonal treatment: The mare's follicle was regularly examined by rectal ultrasonography to confirm ovulation. Artificial insemination using chilled semen was performed before the second and fifth ovulations after hormonal treatment. When the mare's follicle reached a diameter of $35 \mathrm{~mm}$ and had a soft consistency, human chorionic gonadotropin (hCG; 2,500 IU; Gonatropin 3000, Aska Pharmaceutical Co., Ltd., Tokyo, Japan) was administered by intravenous injection. The mare was then inseminated $30 \mathrm{hr}$ after receiving the hCG. The chilled semen collected within $24 \mathrm{hr}$ before insemination was deposited into the uterine body. The persistence of the dominant follicle was confirmed by rectal ultrasonography before insemination. Furthermore, the mare's follicle was examined to confirm ovulation $18 \mathrm{hr}$ after the insemination. Ultrasonographic diagnosis of pregnancy was performed 15 days after ovulation.

Adoption of the orphan foal: Vaginal-cervical stimulation (VCS) was performed by the method of a previous report [28]. The orphan foal was held close to the adoptive mare's head in the stock, while the mare underwent two 3-min periods of VCS separated by a 10 -min interval. Vaginal-cervical stimulation consisted of manual massage by a person's hand and forearm inserted into the mare's vagina. On the first day of adoption, the mare was kept in the nursing chute, similar to a simplified stock, which was built in the corner of the stall, so that the mare could not spin around to kick or bite at the foal, while allowing the foal to run freely and suckle. This simplified stock was built so that a simple metal tube 
Table 1. Protocol for inducing lactation in a barren parous mare by hormonal treatment

\begin{tabular}{ll}
\hline \multicolumn{1}{c}{ Day } & \multicolumn{1}{c}{ Hormonal Treatment } \\
\hline $1-14$ & Altrenogest (72 mg/day per os), Estradiol-benzoate (7.1 mg/day i.m.) \\
8 & Estradiol-benzoate (50 mg i.m.), Prostaglandin (5 mg i.m.) \\
$8-22$ & Sulpiride (1 mg/kg, BID. i.m.) \\
\hline 14 & Introducing to an orphan foal \\
\hline
\end{tabular}

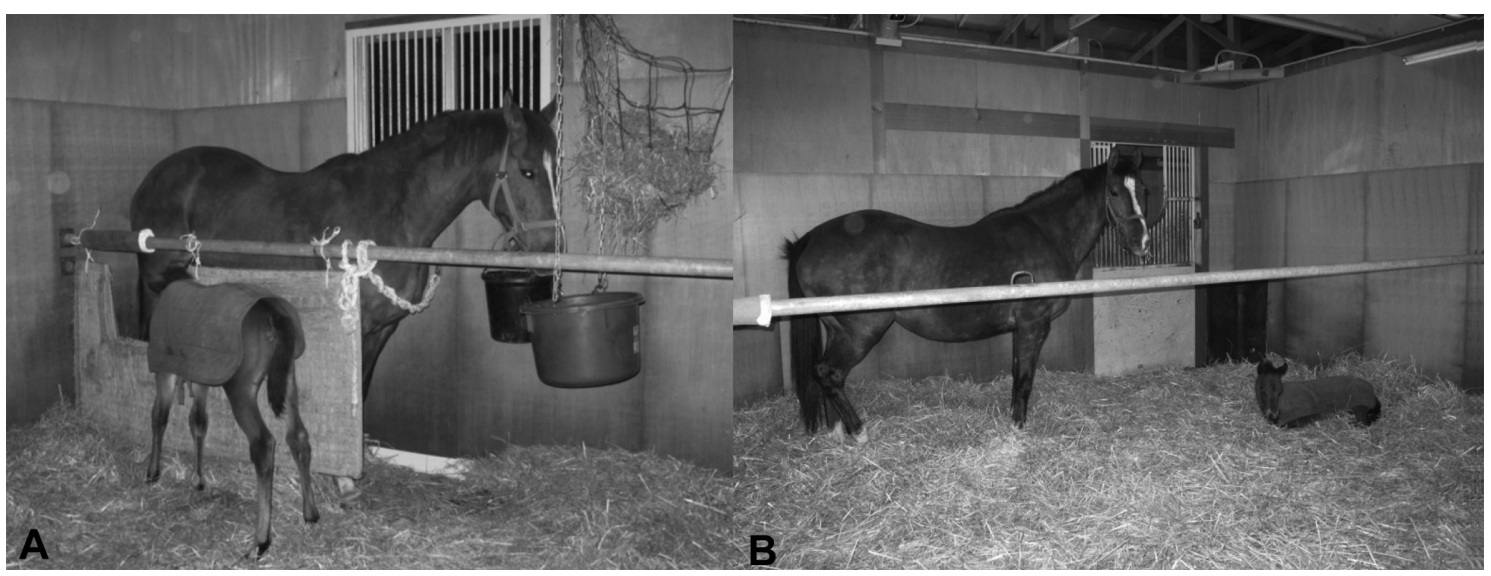

Fig. 1. Photographs of the simplified stock that was built in the stall (A), which was made with a simple metal tube that was placed at the level of the mare's stifle with a hole in the lateral panel at the level of the udder for the foal to suckle, and a simple metal tube that was placed horizontally at the mare's chest height in the middle of the stall (B), which makes it possible to separate the space between the mare and the orphan foal and to prevent the mare from kicking or biting the foal.

was placed at the level of the mare's stifle and was solidly attached to both lateral walls of the stall, with a hole in the lateral panel at the level of the udder for the foal to suckle (Fig. 1A). From the second day of adoption, a simple metal tube was placed horizontally at the mare's chest height in the middle of the stall and was solidly attached to both lateral walls of the stall (Fig. 1B), so that the mare could not move into the foal's space separated by the metal and could not kick or bite the foal, because she allowed him to suckle only when restrained by an attendant, although she sometimes showed aggressiveness toward him without an attendant.

Growth rate of the foal: To determine the growth rate of the foal adopted by the mare with induced lactation, the foal was weighed weekly from 1 week to 52 weeks old. Seven foals, which were kept on the same farm and raised by their natural mothers, were used as controls.

Blood sampling: Blood samples were collected in heparinized tubes daily from the day before the beginning of hormonal treatment to Day 58 after the beginning of hormonal treatment. Blood samples were centrifuged and plasma was stored at $-20^{\circ} \mathrm{C}$ until analysis.

Hormone assay: Prolactin (PRL). The measurement method for PRL in mare plasma was constructed using a homologous radioimmunoassay system as described previously [8], using a rat anti-sera against equine PRL (AFP261987) and iodinated equine PRL (AFP8794B) and reference standard (AFP7730B) (provided by Dr. A. F. Parlow). The intra- and inter-assay coefficients of variation were 4.3 and $8.7 \%$, respectively.

Progesterone and estradiol-17 $\beta$. Plasma concentrations of progesterone and estradiol-17 $\beta$ were determined by time-resolved fluoroimmunoassay (TR-FIA) using DELFIA systems (PerkinElmer, Waltham, MA, U.S.A.) according to the manufacturer's protocol with minor modification $[12,24]$. Briefly, assay buffer containing $\sim 566.7 \mathrm{ng} / \mathrm{ml}$ of europium (Eu)-labeled progesterone and $\sim 11.3 \mathrm{ng} / \mathrm{ml}$ of anti-progesterone antibody were added at the same time and incubated for $2 \mathrm{hr}$. In the estradiol-17 $\beta$ assay, the assay buffer contained $\sim 62.5 \mathrm{ng} / \mathrm{ml}$ of Eu-labeled estradiol-17 $\beta$ and $\sim 11.3 \mathrm{ng} / \mathrm{m} l$ of rabbit anti-estradiol-17 $\beta$ antibody. Samples and standard reagents were incubated with Eu-labeled estradiol-17 $\beta$ in anti-rabbit IgG antibody-coated plate wells for $2 \mathrm{hr}$. Rabbit anti-estradiol-17 $\beta$ antibody was then added and the plate was incubated for an additional $4 \mathrm{hr}$. After incubation, each well was washed with DELFIA Platewash washing buffer. Enhancement solution was then added, incubated for $5 \mathrm{~min}$, and fluorescence from the dissociated europium was detected using a time-resolved fluorometer (Wallac 1420 ARVO MX; PerkinElmer). Concentrations of steroids in plasma were calculated using computer software (Multicalc, PerkinElmer). The intra- and inter-assay coefficients of variation were 5.5 and $8.6 \%$ for progesterone and 4.6 and $9.4 \%$ for estradiol- $17 \beta$.

Follicle-stimulating hormone and luteinizing hormone. 
Plasma concentrations of FSH [23] and LH [7] were determined by homologous double-antibody equine radioimmunoassay methods as described previously. Intra- and interassay coefficients of variance were 4.9 and $12.2 \%$ for FSH and 12.6 and $15.1 \%$ for $\mathrm{LH}$, respectively.

Experiment 2: Evaluating the Possibility of BecomingPpregnant

Animal: In one Thoroughbred mare that was 9 years old, $568 \mathrm{~kg}$ body weight, non-pregnant, non-parturient, and had previously delivered and nursed five foals, lactation was induced by hormonal treatment. The mare was housed at night, grazed every day, and was fed three times a day based on the calculated requirements (approximately $31 \mathrm{Mcal}$ ) for natural nursing mares from the first day of hormonal treatment. The mare was kept under an artificial photoperiod (14.5 hr light: $9.5 \mathrm{hr}$ darkness; light intensity: $100 \mathrm{lux}$ ) for about 11 weeks before the start of hormonal treatment, with January 5th as the start date. Furthermore, this artificial photoperiod treatment was maintained until the first ovulation after the end of hormonal treatment.

Hormonal treatment: Hormonal treatment was performed in the same way as in the first study (Table 1). Milking was started on Day 9 and performed five times per day between 0600 and 1900 by hand. The quantity of milk production was measured each time.

Artificial insemination after hormonal treatment: Artificial insemination using chilled semen was performed before the first ovulation after hormonal treatment in the same way as in the first study. Ultrasonographic diagnosis of pregnancy was performed 15 days after ovulation.

\section{RESULTS}

Experiment 1: Case Report on the Induction of Lactation and Introduction of that Mare to an Orphan Foal

Milk production: The daily milk production was $160 \mathrm{ml}$ on the first day, $900 \mathrm{~m} l$ on the second day, and 1,900 $\mathrm{m} l$ on the third day of milking. Because the milk production of the fourth day of milking reached $800 \mathrm{ml}$ in the first milking of the day, this result determined that the mare was suitable to be a nurse mare to raise the orphan foal. Thus, the mare with induced lactation was introduced to the orphan foal on Day 14 after the beginning of hormonal treatment. Change in the udder size of the mare with induced lactation before and after hormonal treatment is shown in Fig. 2.

Adoption of the orphan foal: The mare showed maternal behavior, such as licking, toward the orphan foal in this study during VCS treatment. However, the mare did not allow the foal to suckle and sometimes showed aggressiveness toward the foal without an attendant for 5 days after adoption. When the mare and the foal were turned out into the pasture with another mare and foal on the sixth day after adoption, the mare tried to protect the foal from the threat of the other mare and then immediately allowed the foal to suckle without an attendant. After that, the mare fully accepted the foal and her maternal behavior toward the foal was maintained until weaning. It took 5 days after adoption for the mare with induced lactation to accept the orphan foal fully.

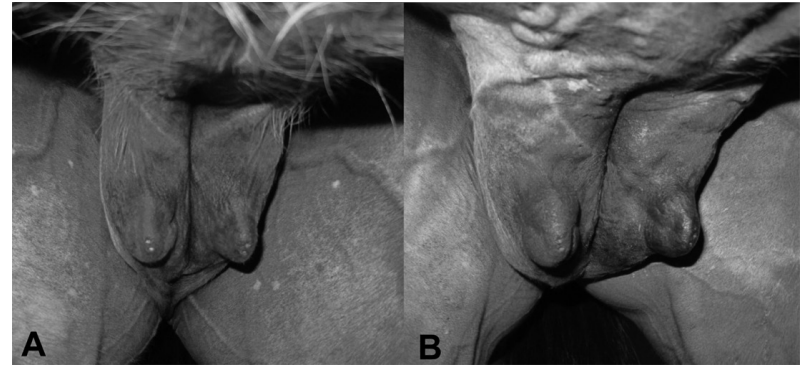

Fig. 2. Photographs of the udder size before hormonal treatment (A) and just before introduction to an orphan foal on Day 14 after the beginning of hormonal treatment (B).

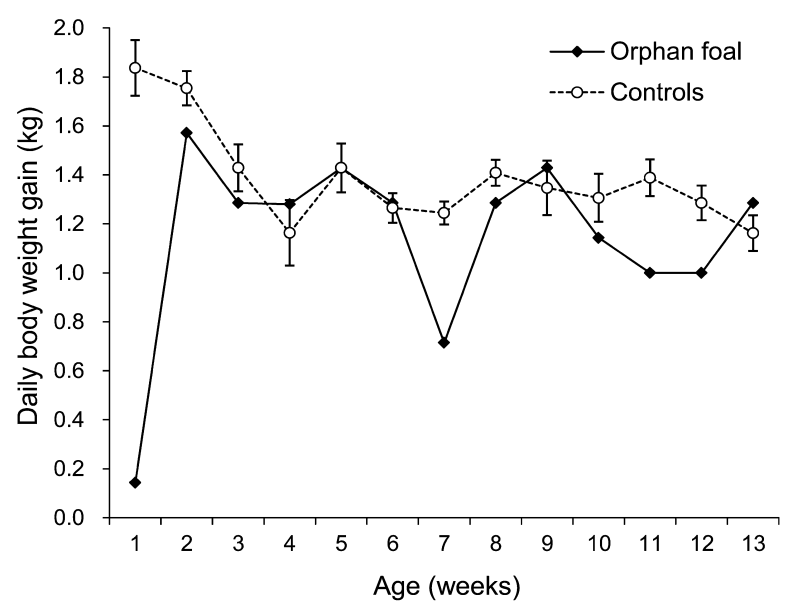

Fig. 3. Changes in daily body weight gain until 13 weeks old of the orphan foal compared with that of control foals. Results of control foals represent the mean and SEM.

Growth rate of the foal: The daily body weight gain of the adopted foal was clearly lower than that of the control group foals during the first week after birth, because the foal could not suckle as the result of rejection by his own dam (Fig. 3). During the period of feeding with artificial milk before the mare with induced lactation was introduced to the orphan foal from the second week to the third week, the daily body weight gain of the adopted foal tended to be the same as that of the control group foals. Also, after the fourth week, when the mare with induced lactation was introduced to the orphan foal, the daily body weight gain of the adopted foal tended to be the same as that of the control group foals, except in the seventh week, when the foal was affected by pneumonia (Fig. 3).

The body weights of the adopted foal and control group foals from 1 week to 52 weeks old are shown in Fig. 4. The difference in body weight between the adopted foal and the control foals was $8 \mathrm{~kg}$ at 1 day old, probably because of the primiparous foal. The maximum difference in body weight was $29 \mathrm{~kg}$ at 12 weeks old. The difference in body weight gradually decreased as the weeks passed and was $17 \mathrm{~kg}$ at 24 weeks old, the age of weaning. Furthermore, the weights 


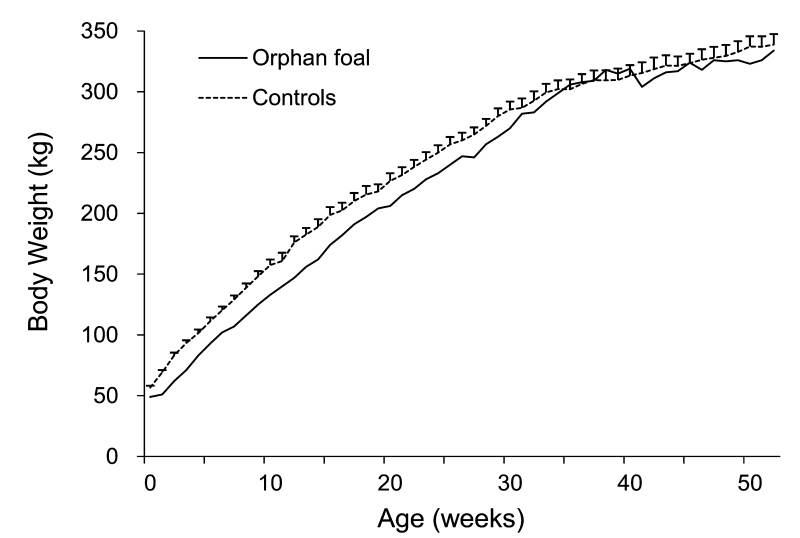

Fig. 4. Changes in body weight until 52 weeks old of the orphan foal compared with that of control foals. Results of control foals represent the mean and SEM.

were nearly the same at 35 weeks old and later.

Ovulation and pregnancy after hormonal treatment: The first ovulation of the mare with induced lactation after hormonal treatment was confirmed on Day 24, which was 10 days after the end of hormonal treatment and 3 days after the end of sulpiride treatment, determined by rectal ultrasound examination. Subsequently, the normal estrous cycle resumed and ovulation was confirmed on Days 44, 59, 74, and 84. Prostaglandin was administered to the mare to shorten the estrous cycle between Days 74 and 84 . Artificial insemination was performed on Day 43; however, conception was not confirmed 15 days after ovulation. Artificial insemination was performed again on Day 83 and conception was confirmed 15 days after ovulation.

Hormone profiles: Change in plasma concentrations of PRL. Plasma concentrations of PRL were low before sulpiride treatment (ranging from 1.5 to $3.0 \mathrm{ng} / \mathrm{m} l$ ), increased during treatment (ranging from 14.5 to $54.8 \mathrm{ng} / \mathrm{m} l$ ), and returned to a low level when treatment was stopped (Fig. 5A).

Changes in plasma concentrations of progesterone and estradiol-17 $\beta$. Changes in plasma concentrations of progesterone and estradiol-17 $\beta$ are shown in Fig. 5B. Plasma concentrations of progesterone gradually increased during altrenogest treatment from Days 1 to 8 and rapidly decreased to $1.9 \mathrm{ng} / \mathrm{m} l$ on Day 9 after the administration of prostaglandin on Day 8. It remained less than $1.0 \mathrm{ng} / \mathrm{m} l$ during sulpiride treatment. Plasma progesterone profiles showed normal estrous cyclic variations after the end of all treatments and progesterone levels increased after ovulation on Days 24 and 44. Plasma concentrations of estradiol- $17 \beta$ remained over 20 $\mathrm{pg} / \mathrm{m} l$ during estradiol-benzoate treatment from Days 1 to 14 and reached high levels on Days 9 and 10 after administration of high concentrations of estradiol-benzoate on Day 8 .

Changes in plasma concentrations of FSH and LH. Changes in plasma concentrations of FSH and LH are shown in Fig. 5C. Plasma concentrations of FSH rapidly increased to $19.0 \mathrm{ng} / \mathrm{m} /$ on Day 11 and then gradually decreased until the first ovulation after the end of all treatments. Then, decreases in plasma concentrations of FSH were observed during the

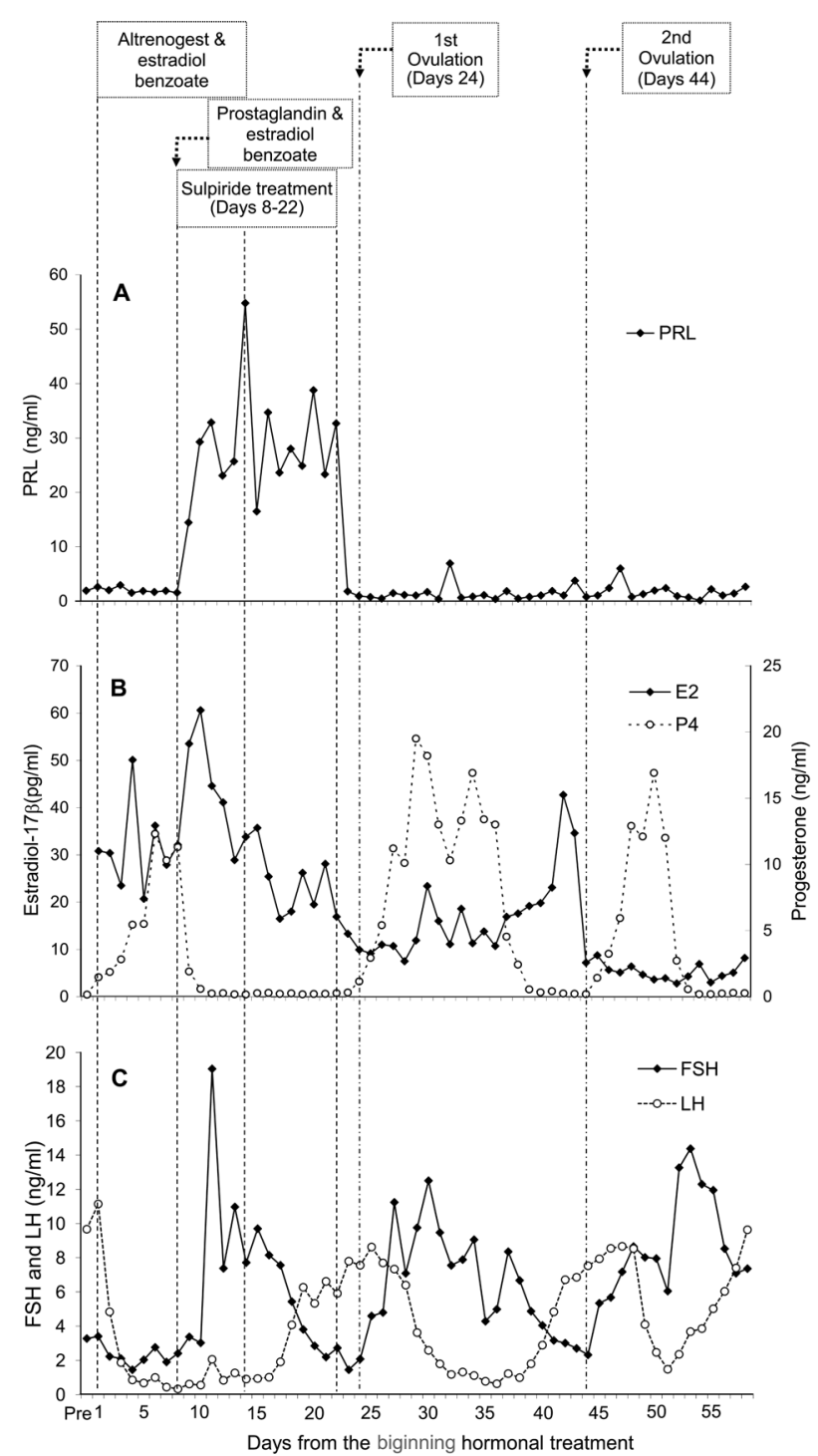

Fig. 5. Changes in serum prolactin concentration (A), serum progesterone and estradiol- $17 \beta$ concentrations (B), and serum folliclestimulating hormone and luteinizing hormone concentrations (C) every day from the day before the beginning of hormonal treatment to 58 days after the beginning of hormonal treatment in the mare with induced lactation.

follicular phase of the estrus cycle. Plasma concentrations of LH reached the peak level on Day 1 and rapidly decreased. After the end of altrenogest and estradiol-benzoate treatments on Day 14, normal estrous cycle variations returned and hormones increased a few days before the onset of estrus to a peak shortly after ovulation.

Experiment 2: Evaluating the Possibility of Becoming Pregnant after End of Hormonal Teatment

Ovulation and pregnancy after hormonal treatment: The first ovulation of the mare with induced lactation after hormonal treatment was confirmed on Day 19 , which was 5 days after the end of hormonal treatment, demonstrated by 
rectal ultrasound examination. Artificial insemination was performed on Day 18 and conception was confirmed 15 days after ovulation.

\section{DISCUSSION}

The present study is the first to demonstrate that a barren parous Thoroughbred mare with induced lactation can be introduced to an orphan foal as a nurse mare and can raise the orphan foal until the weaning age. The present study also showed that the mare with induced lactation could become pregnant after the end of treatment for induction of lactation and the hormone profiles returned to their regular pattern after the first ovulation. Furthermore, the results of our present study suggested that induced lactation in a barren mare as a nurse mare in a Thoroughbred farm is a useful method for solving the high cost of leasing a nurse mare and preventing epidemics in introducing a nurse mare from another farm to an orphan foal.

Thoroughbreds are considered to be very special horses, because they are purebred, "hot-blooded", highly valued, and used mainly for racing. Owners of Thoroughbred racehorse farms prefer to raise their orphaned foals of Thoroughbred racehorses by mild-mannered nurse mares, such as Paints, Appaloosas, and Quarter Horses, because hand-raised foals often tend to have delayed growth and seem to become difficult to manage. The successful placement of an orphan foal with a nurse mare ensures not only adequate growth, but also proper socialization. On the other hand, if nurse mares of different sizes, such as heavy breeds, are introduced to Thoroughbred orphan foals, they are often overfed and this may lead to an increase in growth rate, weight gain, and orthopedic problems [22]. Furthermore, in our opinion, a nurse mare of a different breed and a Thoroughbred orphan foal sometimes isolate themselves from other Thoroughbred mares and foals in the same pasture due to the differences in temperament, exercise volume, and feeding behavior. This may lead orphan foals to have decreased exercise volume and physical capacity until weaning. For these reasons, we believe that it is better for Thoroughbred orphan foals to be raised by Thoroughbred nurse mares from the point of view of their future as a racehorse. However, there has been no previous report to demonstrate that Thoroughbred mares with induced lactation by hormonal treatment can raise orphan foals because their full maternal behavior is regarded as difficult to induce due to their nervous temperament.

Full maternal behavior, including acceptance at the udder and nursing, is as important as the amount of milk production when the mare with induced lactation raises the orphan foal. Although an orphan foal does not usually present any problem during adoption because a hungry foal will attempt to suck from any mare, inducing full maternal behavior relies on deceiving the mare's senses into perceiving that an orphan foal could be her own. In mammals, the physiological events during parturition play an important role in the development of maternal behavior. General maternal behavior is considered to be triggered by hormonal priming with progesterone or estradiol, release of oxytocin or PRL, and olfactory cues, although these may vary among species $[11,17,18,25,26]$. Furthermore, the ability of mothers to display a well-adapted maternal behavior is also modulated by maternal experience gained at the first parturition [25]. A previous report demonstrated that latencies to accept suckling attempts by a foster foal were reduced markedly by VCS treatment [28], which presumably reflects the surge of oxytocin resulting from physical stimulation that is normally associated with parturition, such as in ewes $[19,20$, 27]. Similarly, the mare also showed maternal behavior, such as licking, toward the orphan foal during VCS treatment in our present study. However, the mare did not allow the foal to suckle and sometimes showed aggressiveness toward the foal without an attendant for 5 days after adoption. A previous report demonstrated that an adoptive mare with VCS adopted her foster foal within $1.5 \mathrm{hr}$ and an adoptive mare without VCS adopted her foster foal within $20 \mathrm{hr}$ [28]. Thus, previous study results were significantly different from those in our study. These differences probably reflect the difference in breed of horses, Welsh pony (previous report) vs. Thoroughbred racehorse (our study), rather than a difference in technical methods.

On the other hand, there are several reports that maternal behavior can be induced by another horse approaching, especially a male horse, because the mare may be stimulated to be protective of the foal with the threat of another horse $[10,22]$. In our present study, this method for induction of maternal behavior was performed on the sixth day after adoption. As soon as the mare and the foal were turned out into the pasture with another mare and foal, the mare tried to protect the adopted foal from the threat of other horse. After that, the mare immediately allowed the foal to suckle without an attendant. This reaction is thought to be based on the protective nature of the mare. In mammals, the capacity to raise offspring, such as protecting offspring from predators and providing the only source of food for several days or weeks, is also a critical element, even though fertilization is the first vital step for breeding success, which can be defined by a mammal's aptitude to transmit its genes to the following generation of a population [25]. This result suggested that the method of encouraging the protective nature toward offspring by allowing other horses to approach might be better for inducing full maternal behavior than the method of stimulating the internal maternal factors during parturition when a nurse mare, especially a nervous mare such as Thoroughbred, is introduced to an orphan foal. This may be due to the nature of mare and foal bonding. In fact, a foal follows its dam within hours after birth, while the neonates of cattle and goats remain at the birth site when their dams leave to graze, returning to nurse their offspring [14]. The mare's behavior changes when the foal lies down; the mare does not continue walking, but instead stands over the foal [14].

The quantity of milk obtained before the adoption of the orphan foal gradually increased as the days passed and reached $800 \mathrm{ml}$ in the first milking of Day 14, just before the adoption of the orphan foal. The obtained milk volumes per milking after correction for body weight were lower than those of naturally lactating mares [9], but were comparable 
with those of mares with induced lactation [2]. A previous report suggested that a mare with induced lactation was ready for adoption when milk production reached 3 to 5 $l$ per day for a $500-\mathrm{kg}$ horse [4]. In our present study, the quantity of milk obtained before the adoption of the orphan foal was adequate to meet the energy demand of the foal. On the other hand, sulpiride treatment should be continued for 7 to 10 days after adoption and artificial milk should be supplemented to the adopted foal 3 to 5 times per day (1-2 $l$ each time) until the foal refuses the artificial milk, because the milk production of the mare with induced lactation may not be sufficient. Therefore, in our present study, sulpiride treatment was continued for 8 days after adoption and the foal was supplemented with approximately $5 l$ of artificial milk for 3 weeks after adoption. A previous report demonstrated that adopted foals had a significantly lower daily body weight gain than control foals during the first 4 weeks after adoption and a significantly lower body weight than control foals at 60 days old, but a similar body weight compared to control foals at weaning age [5]. In the present study, the difference in body weight between the adopted foal and control foals was $17 \mathrm{~kg}$ at 24 weeks old, the age of weaning, and body weight was similar between the adopted foal and control foals after 35 weeks old. This result, which suggested that an adopted foal took more time to reach a similar body weight as the control foals compared to a previous study, may be because the difference in body weight between the adopted foal and control foals was already $8 \mathrm{~kg}$ from the primiparous foal and because the foal was afflicted with pneumonia in the seventh week, rather than because the mare did not produce sufficient milk.

Prolactin is the main hormone for inducing lactation in equine species and dopamine is the most important PRLrelease inhibiting factor. Therefore, a dopamine antagonist, such as sulpiride or domperidone, which dramatically increases plasma PRL concentration, can be used to prevent the plasma PRL decrease induced by ergot alkaloids and can be used to restore lactation in affected mares [29]. In our present study, plasma PRL concentrations also increased during treatment and returned to the basal level immediately after the end of treatment, but the mare still produced a sufficient amount of milk and was able to raise the foal until weaning, just as typical parturient mares do. This result supports the hypothesis of previous studies [15, 32], which states that the sudden increase in plasma PRL concentrations as shown in healthy gestation could be the trigger for the onset of lactation.

Based on the result of the hormonal assay, although each hormone profile was affected by hormonal treatment during the administration period, the normal estrous cycle of each hormone profile recovered after the end of all treatments. Additionally, the first ovulation was confirmed after 10 days from the end of hormonal treatment in Experiment 1 and after 5 days in Experiment 2 and conception might be confirmed in the first ovulation in which artificial insemination was performed in Experiment 2. These results suggest that hormonal treatment for induction of lactation has no influence on the reproductive function of mares.
Foal rejection, the primary cause of creating an orphan foal, occurs most often in primiparous mares $[13,16]$. Owners of Thoroughbred farms generally prefer the foal born during the first two months of the year because of having an advantage in the yearling sale. Therefore, a primiparous mare that was barren in the last year is typically mated early in the season and foal rejection by primiparous mares usually occurs during the first two or three months of the year. Our study suggested that a mare with induced lactation might become pregnant in the first ovulation after the end of hormonal treatment. Furthermore, recent studies indicate that lactation can be induced in mares in a minimum of 1 week by a modified hormonal treatment $[4,31]$. These results mean that a barren parous mare with induced lactation and introduced to an orphan foal as a nurse mare early in the breeding season can give birth in the next season. This promises a considerable amount of economic advantage for the owner of a Thoroughbred farm with an orphan foal, especially in a country such as Japan in which locating a nurse mare can be difficult and leasing a nurse mare can be hugely expensive (e.g., cost is approximately US\$2,000 in the U.S.A. vs. approximately US\$10,000 in Japan to lease a nurse mare until the foal is weaned) (personal communication).

In conclusion, the results of our present study demonstrate that a barren parous mare with induced lactation can be introduced to an orphan foal kept at the same farm as the nurse mare and can raise an orphan foal until weaning age in Thoroughbreds and the mare can become pregnant after the end of hormonal treatment. This approach is useful for solving the economic and epidemic problems of introducing a nurse mare to an orphan foal.

ACKNOWLEDGMENTS. We are grateful to the National Hormone and Pituitary Program of the National Institute of Diabetes and Digestive and Kidney Diseases of the United States National Institutes of Health (Torrance, CA, U.S.A.) and Dr. A. F. Parlow for providing the equine LH, FSH, and PRL RIA kits.

\section{REFERENCES}

1. Chakriyarat, S., Head, H. H., Thatcher, W. W., Neal, F. C. and Wilcox, C. J. 1978. Induction of lactation: lactational, physiological, and hormonal responses in the bovine. J. Dairy Sci. 61: 1715-1724. [Medline] [CrossRef]

2. Chavatte-Palmer, P., Arnaud, G., Duvaux-Ponter, C., Brosse, L., Bougel, S., Daels, P., Guillaume, D., Clement, F. and Palmer, E. 2002. Quantitative and qualitative assessment of milk production after pharmaceutical induction of lactation in the mare. $J$. Vet. Intern. Med. 16: 472-477. [Medline] [CrossRef]

3. Collier, R. J., Bauman, D. E. and Hays, R. L. 1977. Effect of reserpine on milk production and serum prolactin of cows hormonally induced into lactation. J. Dairy Sci. 60: 896-901. [Medline] [CrossRef]

4. Daels, P. F. 2006. Induction of lactation and adoption of the orphan foal. In: Proceedings of 8th Annu. Conv. Am. Assoc. Equine Practnr. Annu. Resort Symposium.

5. Daels, P. F., Duchamp, G., Massoni, S. and Chavatte, P. 2002. 
Induction of lactation in non-foaling mares and growth of foals raised by mares with induced lactation. Theriogenology 58: 859-861. [CrossRef]

6. Daels, P.F., Duchamp, G. and Porter, D. 2002. Induction of lactation and adoption of foals by non-parturient mares. pp. 68-71. In: Proceedings of 48th Annu. Conv. Am. Assoc. Equine Practnr.

7. Dhakal, P., Tsunoda, N., Nakai, R., Nagaoka, K., Nambo, Y., Sato, F., Taniyama, H., Watanabe, G. and Taya, K. 2011. Post-natal dynamic changes in circulating follicle-stimulating hormone, luteinizing hormone, immunoreactive inhibin, progesterone, testosterone and estradiol-17 $\beta$ in throughbred colts until 6 months of age. J. Equine Sci. 22: 9-15. [CrossRef]

8. Dhakal, P., Tsunoda, N., Nakai, R., Kitaura, T., Harada, T., Ito, M., Nagaoka, K., Toishi, Y., Taniyama, H., Watanabe, G. and Taya, K. 2011. Annual changes in day-length, temperature, and circulating reproductive hormones in thoroughbred stallions and geldings. J. Equine Sci. 22: 29-36. [CrossRef]

9. Doreau, M., Boulot, S., Martin-Rosset, W. and Dubroeucq, H. 1986. Milking lactating mares using oxytocin: milk volume and composition. Reprod. Nutr. Dev. 26: 1-11. [CrossRef]

10. Elkanah, H., Grogan, B. and McDonnell, S. M. 2005. Evaluation of a new test kit for estimating the foaling time in the mare. Clin. Tech. Equine Pract. 4: 228-237.

11. Gonzalez-Mariscal, G. 2001. Neuroendocrinology of maternal behavior in the rabbit. Horm. Behav. 40: 125-132. [Medline] [CrossRef]

12. Haneda, S., Nagaoka, K., Nambo, Y., Kikuchi, M., Nakano, Y., Matsui, M., Miyake, Y., Macleod, J. N. and Imakawa, K. 2009. Interleukin-1 receptor antagonist expression in the equine endometrium during the peri-implantation period. Domest. Anim. Endocrinol. 36: 209-218. [Medline] [CrossRef]

13. Houpt, K. A. 1984. Foal rejection and other behavioural problems in the postpartum period. Compend. Contin. Educ. Pract. Vet. 6: 144-148.

14. Houpt, K. A. 2000. Equine maternal behavior and its aberrations. In: Recent Advances in Companion Animal Behavior Problems (Houpt, K.A. ed.), International Veterinary Information Service, New York.

15. Ireland, F. A., Loch, W. E., Worthy, K. and Anthony, R. V. 1991. Effects of bromocriptine and perphenazine on prolactin and progesterone concentrations in pregnant pony mares during late gestation. J. Reprod. Fertil. 92: 179-186. [Medline] [CrossRef]

16. Juarbe-Diaz, S. V., Houpt, K. A. and Kusunose, R. 1998. Prevalence and characteristics of foal rejection in Arabian mares. Equine Vet. J. 30: 424-428. [Medline] [CrossRef]

17. Kendrick, K. M. and Keverne, E. B. 1991. Importance of progesterone and estrogen priming for the induction of maternal behavior by vaginocervical stimulation in sheep: effects of maternal experience. Physiol. Behav. 49: 745-750. [Medline] [CrossRef]

18. Kendrick, K. M., Keverne, E. B. and Baldwin, B. A. 1987. Intracerebroventricular oxytocin stimulates maternal behaviour in the sheep. Neuroendocrinology 46: 56-61. [Medline] [CrossRef]
19. Kendrick, K. M., Keverne, E. B., Baldwin, B. A. and Sharman, D. F. 1986. Cerebrospinal fluid levels of acetylcholinesterase, monoamines and oxytocin during labour, parturition, vaginocervical stimulation, lamb separation and suckling in sheep. Neuroendocrinology 44: 149-156. [Medline] [CrossRef]

20. Keverne, E. B., Levy, F., Poindron, P. and Lindsay, D. R. 1983. Vaginal stimulation: an important determinant of maternal bonding in sheep. Science 219: 81-83. [Medline] [CrossRef]

21. King, S. S. and Nequin, L. G. 1989. An artificial rearing method to produce optimum growth in orphaned foals. Equine Vet. Sci. 9: 319-322. [CrossRef]

22. Knottenbelt, D. C., Holdstock, N. and Madigan, J. E. 2004. Fostering the orphan foal. pp. 465-469. In: Equine Neonatology, Medicine and Surgery, WB Saunders, Philadelphia.

23. Medan, M. S., Nambo, Y., Nagamine, N., Shinbo, H., Watanabe, G., Groome, N. and Taya, K. 2004. Plasma concentrations of ir-inhibin, inhibin A, inhibin pro-alphaC, FSH, and estradiol17beta during estrous cycle in mares and their relationship with follicular growth. Endocrine 25: 7-14. [Medline] [CrossRef]

24. Nambo, Y., Tatee, H., Kotoyori, Y., Komano, M. and Tanaka, H. 2009. Weekly changes in serum progesterone concentrations in pregnant thoroughbred mares, in comparison with seven mares with early pregnancy loss. J. Jpn. Vet. Med. Assoc. 62: 630-635 (in Japanese).

25. Poindron, P. 2005. Mechanisms of activation of maternal behaviour in mammals. Reprod. Nutr. Dev. 45: 341-351. [Medline] [CrossRef]

26. Poindron, P., Levy, F. and Krehbiel, D. 1988. Genital, olfactory, and endocrine interactions in the development of maternal behaviour in the parturient ewe. Psychoneuroendocrinology 13: 99-125. [Medline] [CrossRef]

27. Poindron, P., Rempel, N., Troyer, A. and Krehbiel, D. 1989. Genital stimulation facilitates maternal behavior in estrous ewes. Horm. Behav. 23: 305-316. [Medline] [CrossRef]

28. Porter, R. H., Duchamp, G., Nowak, R. and Daels, P. F. 2002. Induction of maternal behavior in non-parturient adoptive mares. Physiol. Behav. 77: 151-154. [Medline] [CrossRef]

29. Redmond, L. M., Cross, D. L., Strickland, J. R. and Kennedy, S. W. 1994. Efficacy of domperidone and sulpiride as treatments for fescue toxicosis in horses. Am. J. Vet. Res. 55: 722-729. [Medline]

30. Smith, K. L. and Schanbacher, F. L. 1973. Hormone induced lactation in the bovine. I. Lactational performance following injections of 17 -estradiol and progesterone. J. Dairy Sci. 56: 738-743. [Medline] [CrossRef]

31. Steiner, J. V. 2006. Induction of lactation in the non-pregnant mare. pp. 91-92. In: Proceedings of 9th Annual Hagyard Bluegrass Equine Symposium.

32. Worthy, K., Escreet, R., Renton, J. P., Eckersall, P. D., Douglas, T. A. and Flint, D. J. 1986. Plasma prolactin concentrations and cyclic activity in pony mares during parturition and early lactation. J. Reprod. Fertil. 77: 569-574. [Medline] [CrossRef] 